\title{
Breeding Season Survival of American Woodcock at a Habitat Demonstration Area in Minnesota
}

\author{
KYLE O. DALY, ${ }^{12}$ Minnesota Cooperative Fish and Wildlife Research Unit, Department of Fisheries, Wildlife, and \\ Conservation Biology, University of Minnesota, St. Paul, Minnesota, USA
DAVID E. ANDERSEN, U.S. Geological Survey, Minnesota Cooperative Fish and Wildlife Research Unit, University of Minnesota, St. Paul, Minnesota, USA

WAYNE L. BRININGER, U.S. Fish and Wildlife Service, Tamarac National Wildlife Refuge, 35704 County Road 26 Rochert, Minnesota, USA

THOMAS R. COOPER, U.S. Fish and Wildlife Service, Migratory Bird Program, 5600 American Boulevard W, Suite 99o, Bloomington, Minnesota, USA

\begin{abstract}
American woodcock (Scolopax minor; hereafter woodcock) best management practices (BMPs) applied at a landscape scale have been proposed to increase woodcock population densities, yet little information exists regarding population vital rates following application of BMPs. We estimated survival rates of woodcock adult females, nests, and juveniles at a woodcock habitat-management demonstration area in west-central Minnesota during the spring and summer (23 March - 30 June) of 2011 and 2012. We radio-marked and tracked 41 adult female and 73 juvenile woodcock, and monitored 51 broods and 48 woodcock nests to determine fates. We used Kaplan-Meier survival analysis to estimate survival rates of females, nests, and juveniles for both 2011 and 2012 and logistic-exposure models to assess relationships between survival and weather covariates, individual life history traits, and vegetation characteristics resulting from BMPs. Breeding season cumulative survival rate for adult females from 1 April - 30 June was 0.695 (95\% CI: $0.357-1.052$ ) in 2011, 0.740 (95\% CI: $0.391-1.091)$ in 2012, and 0.751 (95\% CI: $0.499-1.000)$ when pooling data from both years. Nest survival rate for the 24-day laying and incubation period was 0.458 (95\% CI: $0.299-0.696$ ) in 2011 and 0.786 (95\% CI: $0.616-0.998$ ) in 2012. Cumulative survival rate for juvenile woodcock for a 61-day period (1 May - 30 June) following hatch through mid-summer, when juveniles are independent from adults, was 0.330 (95\% CI: $0.188-0.613$ ) in 2011 and 0.576 (95\% CI: $0.398-0.833$ ) in 2012. In all logistic-exposure survival models, we included a year covariate (females: $\beta_{2011}=-0.16,95 \%$ CI: -1.67 to 1.45 , nests: $\beta_{2011}=-0.768,95 \%$ CI: -1.70 to 0.166 , juveniles: $\beta_{2011}=-0.85,95 \%$ CI: -1.77 to 0.07 ) to account for between-year variation in survival rates, although removing that covariate in models did not result in changes in relations between survival rates and other covariates. Our best-supported model of female survival rate was the null model, suggesting female survival rate was constant across years, and our best-supported model of nest survival rate included only a year covariate. Our best-supported model of juvenile survival rate included the covariates year, juvenile age $\left(\beta_{\mathrm{AGE}}=0.098,95 \%\right.$ CI: 0.04 to 0.16), minimum temperature $\left(\beta_{\mathrm{MINT}}=0.14,95 \% \mathrm{CI}:-0.004\right.$ to 0.28$)$, and precipitation $\left(\beta_{\mathrm{PCPT}}=-0.20,95 \%\right.$ CI: -0.39 to -0.01 ). Juvenile survival rate increased with age and decreased with the amount of precipitation and had a weak positive relation with stem density $\left(\beta_{\text {STEM }}=0.0001,95 \%\right.$ CI: 0.000 to 0.0003$)$. Woodcock in our study almost solely used areas where BMPs had been applied on the landscape within the last 20 years and that had similar vegetation structure; in those settings, only juvenile survival rate was related to local environmental conditions.
\end{abstract}

Proceedings of the American Woodcock Symposium 11: 45-63

1 email: kyle_daly@fws.gov

2 current address: U.S. Fish and Wildlife Service, Wildlife and Sport Fish Restoration Program,

5600 American Boulevard W, Suite 99o, Bloomington, MN 55437 
KEY WORDS: American woodcock, brood, female, habitat, juvenile, Minnesota, nest, population, Scolopax minor, survival

American woodcock (Scolopax minor; hereafter woodcock) have experienced long-term population declines in the Eastern and Central Management Regions (o.8 $\%$ per year) since American Woodcock Singing-ground Surveys (SGS) were first implemented in the mid-196os (Seamans and Rau 2016). These declines in population size are coupled with declines in woodcock recruitment across their range (indexed through juvenile/adult female ratios derived from wing-collection surveys; Seamans and Rau 2016). Extensive loss or alteration of breeding habitat, characterized by young regenerating forested areas with interspersed open grassy or cleared areas, has been suggested as the main cause of these declines (Dwyer et al. 1988, Gregg 1984, Sauer and Bortner 1991, Kelley et al. 2008, Wildlife Management Institute 2009). Kelley et al. (2008) proposed stabilizing and ultimately increasing the size of woodcock populations by increasing woodcock density on portions of the primary breeding range to that observed during the 1970s. As part of that effort, a system of woodcock habitat demonstration areas has been developed throughout the primary woodcock breeding range where specific best management practices (BMPs) are applied (Wildlife Management Institute 2010). These areas are meant to demonstrate management practices to increase the amount and improve the quality of existing breeding habitat to encourage increases in woodcock breeding population density and size.

Application of BMPs at a demonstration-area scale ( 200-80o ha) is designed to positively influence woodcock population growth by improving habitat quality and abundance at a landscape scale. BMPs create or maintain young forest cover through clear-cutting, timber harvest, shearing of brush and small trees, and prescribed burning (Wildlife Management Institute 2009). BMPs are applied at specific sites within the larger landscape, but when applied at multiple locations at the demonstration-area scale, they create a juxtaposed mosaic of young forest cover of different age classes that provides courtship, nesting, brood-rearing, and diurnal feeding habitat for woodcock. Woodcock abundance is known to increase in response to vegetation management (Dwyer et al. 1988, McAuley et al. 1996); therefore, increasing the amount of young forest cover at the demonstration-area scale is assumed to increase woodcock population size. The influence of BMPs applied at a landscape scale on woodcock vital rates is not well understood in the Central Management Region, although there are some woodcock survival-rate estimates in the eastern portion of the woodcock breeding range where BMPs have been applied (Dwyer et al. 1988; McAuley et al. 1996, 2010; Longcore et al. 2000). These studies were completed prior to the establishment of demonstration areas, making it dif- ficult to relate survival rates with application of BMPs at the demonstration-area scale.

We evaluated woodcock vital rates in an area where BMPs were applied at the demonstration-area scale in the western portion of the woodcock breeding range by assessing adult female, nest, and juvenile survival rates and factors associated with these rates. Our specific objectives were to (1) describe characteristics of nest sites and locations used by woodcock broods potentially related to survival rates, (2) estimate adult female, nest, and juvenile survival rates of woodcock at a demonstration-area scale, and (3) assess relationships between survival rates and vegetation structure (e.g., stem density, distance to edge, and basal area) resulting from BMPs, life history traits (e.g., date of nest initiation, number of nesting attempts, and female reproductive status), and weather (e.g., precipitation, maximum temperature, and minimum temperature). We expected that woodcock survival rates would be positively related to conditions resulting from BMPs applied at a demonstration-area scale, and that survival rates would be related to characteristics of cover types, life history, and weather, based on relationships reported previously (e.g., Dwyer et al. 1988).

\section{Study Area}

We conducted our study at the Tamarac National Wildlife Refuge (NWR), located near Rochert, Minnesota, USA (47.0 N, -95.7 E), during spring and summer 2011 and 2012. Tamarac NWR lies in the glacial lake country of west-central Minnesota in Becker County and encompasses 17,296 ha dominated by forests, intermingled with lakes, rivers, marshes, shrub swamps, and tallgrass prairie. Tamarac NWR is located in the transition zone between coniferous forest, northern hardwood forest, and tallgrass prairie. Sixty percent of the refuge is forested; the dominant tree species are aspen (Populus spp.), jack pine (Pinus banksiana), red pine (P. resinosa), balsam fir (Abies balsamea), paper birch (Betula papyrifera), northern red oak (Quercus rubra), white oak (Q. alba), sugar maple (Acer saccharum), and basswood (Tilia americana). A substantial portion of the refuge is managed for early successional forest (consistent with BMPs; Wildlife Management Institute 2009), primarily through timber harvest, shearing, and prescribed fire, to provide courtship, nesting, and brood-rearing habitat for woodcock, golden-winged warblers (Vermivora chrysoptera), and other migratory birds that utilize young forests.

\section{Methods}

\section{CAPTURE AND RADIO TELEMETRY}

In 2011 and 2012 we captured and equipped adult female and juvenile woodcock with VHF radio transmitters at 
Tamarac NWR, where BMPs had been applied during the past 20-year period. In March - June of 2011 and 2012, we used mist nets to capture woodcock during dusk (approximately 1900 to 2300 CDT) when woodcock leave diurnal areas to roost or feed (Sheldon 1971). We determined sex of all woodcock captured based on plumage characteristics (Martin 1964) and radio-marked adult female woodcock using a glue-on backpack-style harness that was $\leq 3 \%$ of their total mass $(\sim 4.8 \mathrm{~g}$, model A5410, Advanced Telemetry Systems, Isanti, MN; McAuley et al. 1993a, 1993b). We relocated radio-marked female woodcock from the time that we released them through late June or early July of each year to estimate survival rate during the courtship, nesting, and brood-rearing periods, and for the beginning of the period following brood break-up and prior to migration. We relocated radio-marked female woodcock 5-7 days per week throughout the breeding season (April - June) and into the beginning of the pre-migration season (July - October). We lost radio contact with some females when they traveled long distances, out of the range of our receiving equipment and monitoring protocol. We continued searching for these females throughout our field season and if we did not relocate them, we classified these females as "lost." When we relocated an adult female radio-marked woodcock, we assessed its status (i.e., alive or dead) and assigned it to 1 of 4 categories related to reproduction: pre-nesting, incubating, brood-rearing, or pre-migration. If a radio-marked woodcock was dead when relocated, we assessed the cause of death, and if possible, assigned the cause of death as either mammalian or avian predation using methods described by McAuley et al. (2005). Pre-nesting included the time from capture until egg laying and also the period between nest or brood loss and renesting. If a female renested following a failed nesting or brood-rearing attempt, we categorized her status as pre-nesting between loss of eggs or young and initiation of another nesting attempt. Incubation was the period between the beginning of egg laying and either loss of the nest or until eggs hatched. Brood rearing was the period from when eggs hatched to the loss of all juveniles in the brood or fledging ( 15 days post-hatch). Pre-migration was the period from the end of breeding activity (i.e., date of fledge or loss of a brood or nest without a re-nesting attempt) until we last knew whether a female woodcock was alive or dead.

We found woodcock nests using trained pointing dogs (McAuley et al. 1993a) and via monitoring radio-marked adult females. We visited each nest at 2-3 day intervals and assessed the status of the nest as active, depredated, abandoned, or successful. If the female was not present at the nest or flushed during our visit, we floated any eggs present in ambient-temperature water to estimate nest age and initiation date (Ammann 1974). We considered nests to be active when the adult female was engaged in egg-laying or incubation, or if a female was incubating at a subsequent visit. We categorized nests as depredated if eggs were broken or absent prior to the estimated hatch date. We categorized nests as abandoned if the female was not observed incubating for 2 consecutive visits. We categorized nests as successful if there was evidence that $\geq 1$ eggs hatched (i.e., eggshells in or close to the nest bowl and with a longitudinal split).

To estimate survival rate of juvenile woodcock, we assessed the status of juveniles in broods of radio-marked adult females and also radio-marked a sample of juveniles within broods of radio-marked adult females. We used trained pointing dogs to find additional broods of unmarked adult female woodcock (Mendall 1938; Ammann 1974, 1977) and captured and radio-marked juveniles in those broods. We custom fit a micro-transmitter (BD-2NC or BD-2C, Holohil Systems Ltd., Carp, ON and custom transmitters made by Blackburn Transmitters, Nacogdoches, TX) with a whip antenna to captured juvenile woodcock by means of an elastic collar. All transmitter packages were $\leq 3 \%$ of a woodcock's mass (BD- $2 \mathrm{NC}$ transmitters were approximately $0.6 \mathrm{~g}, \mathrm{BD}-2 \mathrm{C}$ transmitters were approximately $1.6 \mathrm{~g}$, and Blackburn transmitters were approximately $0.4 \mathrm{~g}$ ). We attached transmitters to juvenile woodcock with an elastic collar that expanded as the juvenile woodcock grew. We positioned transmitters at the base of a juvenile woodcock's neck with the transmitter antenna lying down the juvenile's back (Daly et al. 2015). Transmitter lifespan was approximately 21 days (17-30 day range) for $\mathrm{BD}-2 \mathrm{NC}$ transmitters, 63 days (49-77 day range) for $\mathrm{BD}-2 \mathrm{C}$ transmitters, and 28 days (24-32 day range) for Blackburn transmitters.

We radio-marked 1-4 juveniles per brood and monitored both marked and unmarked individuals within a brood after locating radio-marked juveniles. We located broods 4-7 days per week via radio telemetry monitoring of either the adult female or juvenile(s). We assessed status (alive or dead) of juveniles and counted both marked and unmarked juveniles to document brood size. We counted the number of individuals in the brood using radio telemetry to approach a radio-marked woodcock to a distance of approximately $5 \mathrm{~m}$ and then encircled the brood until we were certain we detected and counted all brood members. Beginning approximately 15 days after hatching, entire broods often flushed upon our approach, affording us the opportunity to simultaneously count the number of juveniles in a brood. Beyond 15 days post-hatch, the probability of detecting all members of the brood diminished as individuals from broods became more dispersed until we no longer considered them associated with one another. Federal and State permits for capture, banding, and radio-marking were granted by the U.S. Geological Survey Bird Banding Laboratory (Permit no. 06258, Wayne Brininger), and by the Minnesota Department of Natural 
Resources (Permit nos. 17377 and 17973, Wayne Brininger). Capture and marking protocols were approved by the University of Minnesota Institutional Animal Care and Use Committee under Protocol no.1103A97333.

\section{NEST SITE AND BROOD LOCATION VEGETATION}

We measured stem density (STEM), basal area (BAS), and distance to edge (EDGE) at a subset of woodcock brood locations and at all nest locations. We measured vegetation structure using plot-based methods modified from McAuley et al. (1996), centering plots 0.4 ha in area (11.3 m radius) at nests and brood locations. We counted the number of trees in 5 size-classes adapted from James and Shugart (1970) based on diameter at breast height (DBH; $7.6-15.2 \mathrm{~cm}, 15.3-22.9 \mathrm{~cm}, 23.0-38.1 \mathrm{~cm}, 38.2-53.3$, and $>53.3 \mathrm{~cm})$, and estimated basal area $(\mathrm{m} 2 / \mathrm{ha}$, McAuley et al. 1996) by assigning each individual tree the average DBH for its assigned size class using the formula from Avery and Burkhart (2002):

$$
\text { Basal Area }=0.00007854 \times \mathrm{DBH}^{2}
$$

We then summed basal area for all trees in the plot to estimate basal area for the plot. To estimate woody stem density (stems/ha, McAuley et al. 1996), we established 4 belt transects beginning at the central point of the plot, $3 \mathrm{~m}$ in width and $20 \mathrm{~m}$ in length (0.006 ha), in 1 random azimuth in each quadrant (NE, SE, SW, NW). On each transect, we counted the number of woody stems $<7.6 \mathrm{~cm}$ $\mathrm{DBH}$ and $>1 \mathrm{~m}$ tall within the transect area and pooled the stem counts for the 4 transects to estimate stem density for the plot.

We defined edges as distinct changes in height of forest vegetation that were either anthropogenic (i.e., roads, trails, or forest clearcuts) or natural (i.e., forest openings or wetland edges) and measured distance to edge by visually interpreting changes in forest vegetation height using $1-\mathrm{m}$ resolution aerial photographs (2010 photos) in ArcMap 10.0 (ESRI 2011). We summarized vegetation characteristics by year at both nest sites and brood locations, and compared between years using $\mathrm{t}$-tests.

\section{FEMALE, NEST, AND JUVENILE SURVIVAL RATES}

We used the Kaplan-Meier method with staggered entry (Pollock et al. 1989) using the KMsurv package in Program $\mathrm{R}$ (version 2.15.2, R Core Team, 2012, Vienna, Austria) to estimate survival rate of adult females, nests, and juveniles. We estimated survival rate of adult females, nests, and juveniles separately for 2011 and 2012, because all these vital rates are known to vary temporally. We also estimated adult female survival rate pooled across years to compare our results with other published estimates of female survival rates. We estimated survival rates for the biological period defined by the data for 2011 (11 April - 30 June) and
2012 (1 April - 29 June), then calculated daily survival rate (DSR) estimates from these period survival rate (PSR) estimates. We extrapolated the DSR estimates over the same-length period for 2011 and 2012 to compare survival rate between years. We also estimated female survival rate combined for both 2011 and 2012 using data pooled from both years. For female woodcock we estimated survival rate for a 91-day period (1 April - 30 June). We estimated nest survival rate using a 24 -day period that included 3 days for egg laying and 21 days for incubation. We estimated juvenile survival rate for a 61-day period (1 May 30 June), which represented the period from hatching to mid-summer when juveniles are independent from adult care. Because we were not able to accurately determine the fate of unmarked juveniles after the brood separated ( $\sim 24$ days old), we right-censored unmarked juveniles at 24 days old, which was the earliest we observed brood separation.

We recorded the number of days from when we deployed transmitters on females and juveniles to more accurately censor individuals if radio transmitters failed prematurely. We assumed radios failed if they performed irregularly and there was no other indication an individual had died. We also assumed radios failed if they were nearing the end of their expected battery life and we received no subsequent signals from transmitters. We right-censored individuals in both of these circumstances, assuming the individual survived until transmitter failure (Korschgen et al. 1996).

\section{SURVIVAL RATE MODELS}

For monitored females, nests, and juveniles, we used covariates for year, weather (i.e., maximum temperature, minimum temperature, and precipitation), and attributes of individuals (e.g., juvenile age) to create a set of models of survival rate (see Appendix I for a description of model covariates and expected relationships with survival rates). We also incorporated vegetation-structure covariates (i.e., stem density, basal area, and distance to nearest edge) in models of nest survival rate and juvenile survival rate (see below and Appendix I).

Temporal covariates We included year (YEAR, 2011 or 2012) as a class variable in our models to account for between-year variation in survival rates because survival rates of females, nests, and juveniles can vary among years (Gregg 1984, Longcore et al. 2000, McAuley et al. 2010). We also assessed the influence of the YEAR covariate post hoc by repeating our model selection (see below) procedure without that covariate in our candidate model set. Removing YEAR as a covariate in models did not result in changes in relations between survival and other covariates (unpublished data), and we therefore only report results using models that included YEAR as a covariate. 
Covariates related to weather We included weather covariates in our survival rate models because weather early in the breeding season influences woodcock recruitment (Sepik et al. 2000). We obtained daily weather data from a standard $20.3-\mathrm{cm}$ diameter precipitation gauge and digital temperature logger (Nimbus Digital Thermometer, Sensor Instruments Company Inc., NH) at Tamarac NWR during 2011 and 2012. Precipitation and temperature data were recorded approximately 6 to $8 \mathrm{~km}$ southeast of the location where we monitored woodcock. If precipitation and temperature data from Tamarac NWR were not available, we used weather data from the nearest National Weather Service station in Detroit Lakes, Minnesota (approximately $22 \mathrm{~km}$ southeast of Tamarac NWR). We used the sum of precipitation $(\mathrm{cm})$ for each day in the interval between individual woodcock observations to calculate total interval precipitation (PCPT). We used the recorded maximum (MAXT) and minimum (MINT) temperatures $\left({ }^{\circ} \mathrm{C}\right)$ during each interval between observations in models of survival rate of woodcock females, nests, and juveniles.

Covariates related to individual woodcock Because reproductive status influences behavior and energetic requirements of female woodcock (Rabe et al. 1983), we modeled survival rate including 4 categories of reproductive status (REPRO: pre-nesting, incubating, brood rearing, and pre-migration). We could not clearly define period lengths for each reproductive status because these periods varied with each individual; therefore, we used Mayfield's method (Mayfield 1961, Johnson 1979) to estimate female daily survival rates for reproductive status and compared daily survival rate estimates among reproductive status categories. We also included a covariate indicating whether females were with broods (BROOD) in our models of adult female survival rate.

We included age and hatch date in our models of juvenile survival rate and calculated juvenile age by knowing the hatch date of juveniles or estimating age at capture based on bill-length measurements (Ammann 1982, Sepik 1994). Because intervals between relocations of individual broods were short, we used the age of a juvenile at the midpoint of the interval in our survival rate models. We estimated Julian hatch date (HD) by either monitoring nests of radio-marked females or by aging juveniles at the time of capture and deriving HD based on juvenile age. Because we monitored nests of radio-marked females every 2-3 days, we generally were able to estimate HD within 1 day.

Woodcock are known to readily renest; however, only 1 re-nest per female has ever been observed in a single breeding season (McAuley et al. 1990, KOD personal observation). Woodcock generally renest following a failed nest or if they lose a brood <11 days old (McAuley et al. 1990). We were unable to assess whether most nests in our study were first nests or renesting attempts; therefore, we could not include nesting attempt as a covariate in our analysis. We estimated nest initiation date by floating eggs in ambient-temperature water (Ammann 1974) at nest discovery, or by monitoring nests until hatch and back dating 24 days.

For our survival rate analyses where we were missing covariate data, we used the mean covariate value for that year if $<5 \%$ of the data were missing (e.g., if initiation date was not known for a nest, we used the average nest initiation date for all nests for which we knew the nest initiation date that year). If $\geq 5 \%$ of the data were missing, we excluded all observations with missing covariate data from analysis.

We developed logistic-exposure female, nest, and juvenile survival-rate models (Shaffer 2004) in SAS 9.3 (SAS Institute Inc., NC) to evaluate relationship(s) that considered both weather and individual characteristics (e.g., female reproductive status, see below). We also used logistic-exposure models to assess the relationship(s) between vegetation characteristics and survival rates of nests and juveniles. We evaluated models using a sequential approach (e.g., Amundson and Arnold 2010, Daly et al. 2015) in an information-theoretic framework (Burnham and Anderson 2002). We incorporated YEAR in each model of survival rate of females, nests, and juveniles to assess whether survival rates differed between 2011 and 2012 and to account for reported differences in woodcock survival rates among years (Gregg 1984, Longcore et al. 2000, McAuley et al. 2010; and as noted above, excluding YEAR from models did not change relationships between other covariates and survival rates).

We included a null model (no covariates) in our set of candidate models as a means of evaluating whether including covariates in models of survival rate was supported by our data. During each step of our modeling process subsequent to the initial model, we added covariates to the best-supported model from the previous step individually and in all combinations and ranked models based on Akaike's Information Criterion adjusted for sample size $\left(\mathrm{AIC}_{\mathrm{c}}\right)$ to identify the best-supported model among all candidate models. We defined our best-supported model as the model with the lowest $\mathrm{AIC}_{\mathrm{c}}\left(\Delta \mathrm{AIC}_{\mathrm{c}}=0\right)$ and competing models as any models with $\triangle \mathrm{AIC}_{\mathrm{c}} \leq 2$. We considered covariates uninformative if they did not reduce overall $\mathrm{AIC}_{\mathrm{c}}$ when added to the best-supported model from the previous step (Arnold 2010). We did not consider models containing uninformative covariates to be competitive with our best-supported model, and excluded them from subsequent analyses.

In all of our best-supported models, we used the ESTIMATE statement in SAS 9.3 (SAS Institute Inc., NC) to assess the relationship(s) between daily survival rate and individual covariates in the best-supported model 
by entering multiple values representing the range of observed values for that covariate while holding the other model variables constant at their mean values. We assessed the strength of relationships between survival rates and covariates based on whether $95 \%$ confidence intervals included zero.

Female survival rate models We added reproductive status of female woodcock (REPR) to the model including only YEAR from Step 1 for our second step of modeling female survival rate. We only considered the covariates NEST and BROOD if REPR was an informative variable (i.e., reduced overall $\mathrm{AIC}_{\mathrm{c}}$ when compared with the initial model) in our best-supported model because both NEST and BROOD were correlated with the reproductive status of the female (REPR). For Step 3, we added weather covariates (PCPT, MINT, and MAXT) to our best-supported model from Step 2 to assess the relationship between weather and female survival rate.

Nest survival rate model development We added INIT and NAGE as nest-specific covariates to the model from Step 1 that included only the YEAR covariate. For Step 3, we then added weather covariates to the best-supported model from Step 2 to evaluate the relationship between weather and survival rate of woodcock nests. Finally, in Step 4, we added STEM, BAS, and EDGE to evaluate the relationship between nest survival rate and vegetation characteristics.

Juvenile survival rate model development Survival rate of individual juveniles may not be independent from survival rate of other individuals of the same brood (Chouinard and Arnold 2007, Amundson and Arnold 2010). Therefore, we evaluated whether survival rate was independent among individual juveniles within broods using Winterstein's (1992) third Chi-square goodnessof-fit test (average $P=0.3238$; Appendix 11) in a re-analysis of survival data presented and analyzed in Daly et al. (2015); neither assessment indicated intra-brood dependence among survival rates of brood mates. Daly et al. (2015) also evaluated whether radio transmitters affected survival rate of juveniles and found no evidence of effects on survival rate. We therefore treated individual juveniles as independent samples in subsequent survival rate analyses.

We added JAGE, HD, and the interaction between HD and YEAR to the model from Step 1 that included only the YEAR covariate. We included the interaction between HD and YEAR in models of juvenile survival rate because annual changes in temperature and precipitation affect the timing of woodcock breeding (Murphy and Thompson 1993). Next, in Step 3, we added weather covariates (MAXT, MINT, and PCPT) to the best-supported survival rate model from Step 2 to account for relationships between weather conditions and survival rate of juvenile woodcock.

To evaluate additional relationships between vegetation characteristics and juvenile survival rate, we conducted post hoc analyses by considering STEM, BAS, and EDGE as covariates in models of juvenile survival rate. We assessed these covariates in post hoc analyses because only a subset of juvenile locations had associated vegetation characteristic data. To the best-supported model from our models of juvenile survival rate, we added STEM, BAS, and EDGE singularly and in all possible combinations. We used the best-supported model from our post hoc analysis to assess the relationships between daily juvenile survival rate and covariates included in the model.

\section{Results}

\section{VEGETATION CHARACTERISTICS}

Nest vegetation characteristics We measured vegetation characteristics (stem density, basal area, and distance to edge) at 45 nest locations (Table 1). Nests in 2011 and 2012 had similar stem densities; nests in 2011, however, had greater basal area and were farther from edges than nests in 2012 (Table 1).
Table 1. Comparisons of vegetation characteristics surrounding American woodcock nests in $2011(n=22)$ and $2012(n=23)$ and juvenile American woodcock locations in $2011(n=116)$ and $2012(n=$ 119) at Tamarac National Wildlife Refuge, Rochert, Minnesota, USA.

\begin{tabular}{|c|c|c|c|c|c|}
\hline $\begin{array}{l}\text { Vegetative } \\
\text { characteristic }\end{array}$ & Year & $\overline{\mathbf{x}}(\mathrm{SD})$ & t-statistic & Df & $\mathbf{P}$ \\
\hline \multicolumn{6}{|c|}{ Woody Stem Density (stems/ha) } \\
\hline Nests & 2011 & $12,113(8,358)$ & & & \\
\hline \multirow{3}{*}{ Juveniles } & 2012 & $10,216(4,297)$ & 0.95 & 31 & 0.35 \\
\hline & 2011 & $11,588(5917)$ & & & \\
\hline & 2012 & $13,834(5566)$ & -2.07 & 88 & 0.04 \\
\hline \multicolumn{6}{|c|}{ Basal Area $\left(\mathrm{m}^{2} / \mathrm{ha}\right)$} \\
\hline \multirow[t]{2}{*}{ Nests } & 2011 & $7.7(13.7)$ & & & \\
\hline & 2012 & $29.3(36.9)$ & -2.62 & 28 & 0.01 \\
\hline \multirow[t]{2}{*}{ Juveniles } & 2011 & $11.9(13.9)$ & & & \\
\hline & 2012 & $18.4(17.3)$ & -2.16 & 80 & 0.03 \\
\hline \multicolumn{6}{|c|}{ Distance to Edge (m) } \\
\hline \multirow[t]{2}{*}{ Nests } & 2011 & $45.3(72.2)$ & & & \\
\hline & 2012 & $16.1(23.6)$ & 1.80 & 25 & 0.08 \\
\hline \multirow[t]{2}{*}{ Juveniles } & 2011 & $75.1(86.6)$ & & & \\
\hline & 2012 & $55.6(55.7)$ & 2.04 & 195 & 0.02 \\
\hline
\end{tabular}


Brood-rearing vegetation characteristics We measured vegetation characteristics (woody stem density, basal area, and distance to edge) at 121 woodcock brood locations (2011: $n=66,2012: n=43$ ) representing 45 juvenile woodcock (2011: $n=22,2012: n=23)$ from 14 broods (2011: $n=8$, 2012: $n=6$ ). Woody stem density and basal area at juvenile woodcock locations were higher in 2012 than in 2011 (Table 1). Woodcock brood locations were closer to edges in 2012 than in 2011 (Table 1).

\section{SURVIVAL RATES}

Female survival rates From 9 April to 1 June 2011 and 22 March to 24 May 2012, we captured and radio-marked 41 adult female woodcock (2011: $n=23,2012: n=18)$. We excluded $3(\sim 7 \%)$ radio-marked adult female woodcock in 2011 from survival-rate analysis that we were unable to relocate following radio marking (likely due to transmitter failure or migration). Of the remaining 38 female wood- cock, we right censored 1 female that became entrapped in its radio telemetry harness in 2012.

In 2011 and 2012, we observed 692 intervals and 2,149 exposure days of radio-marked adult female woodcock. Intervals averaged 3.1 days between relocations and ranged from 1 day to 40 days (although intervals were generally short, 1 female left the search area and later returned and was relocated alive after 40 days). Seven of $38(\sim 18 \%)$ adult females were killed by predators during our study (2011: $n=4$, 2012: $n=3$ ). Mammalian predation was the highest source of mortality $(n=4)$, with the remainder attributed to raptors $(n=3)$. Mortalities of female woodcock occurred during pre-nesting $(n=2)$, nesting $(n=2)$, brood-rearing $(n=1)$, and pre-migration periods $(n=2)$. Daily survival rate estimated using Mayfield's method (Mayfield 1961, Johnson 1979) was nearly constant across reproductive status [pre-nesting $=0.9946(95 \% \mathrm{CI}: 0.9871$ - 1.0021), nesting $=0.9958$ (95\% CI: $0.9900-1.0016)$,

Table 2. Comparison of American woodcock survival rate estimates for adult females, nests, and juveniles from Tamarac National Wildlife Refuge, Rochert, Minnesota, USA, in 2011 and 2012, and American woodcock survival rate estimates from previous studies. Period survival rates (PSR) are estimated for the breeding season for adult females and juvenile woodcock. PSR for female woodcock were calculated from daily survival rates (DSR) for a 91-day period, for juvenile woodcock for a 61-day period, and for woodcock nests for 24-day egg-laying and incubation period.

\begin{tabular}{lccl}
\hline PSR $(95 \%$ CI $)$ & DSR $(95 \%$ CI $)$ & Year(s) & Source \\
\hline Females & & & \\
$0.695^{\mathrm{a}}(0.357-1.052)$ & $0.996(0.989-1.001)$ & 2011 & This study \\
$0.740^{\mathrm{a}}(0.391-1.091)$ & $0.997(0.990-1.001)$ & 2012 & This study \\
$0.751(0.499-1.000)$ & $0.997(0.992-1.000)$ & $2011-2012$ & This study \\
$0.913^{\mathrm{a}}(0.833-1.000)$ & $0.999(0.998-1.000)$ & $1982-1984$ & Derleth and Sepik 1990 \\
$0.761^{\mathrm{a}}(0.694-0.913)$ & $0.997(0.996-0.999)$ & $1986-1989$ & Longcore et al. 2000 \\
\hline Nests & & & \\
$0.458^{\mathrm{a}}(0.299-0.696)$ & $0.968(0.951-0.985)$ & 2011 & This study \\
$0.786^{\mathrm{a}}(0.616-1.000)$ & $0.990(0.980-1.000)$ & 2012 & This study \\
$0.62^{\mathrm{b}}$ & & 1943 & Mendall and Aldous 1943 \\
$0.43^{\mathrm{c}}$ & & $1969-1980$ & Gregg 1984 \\
$0.59^{\mathrm{b}}$ & & & \\
\hline Juveniles & & 2011 & This study \\
$0.330^{\mathrm{a}}(0.188-0.613)$ & $0.982(0.973-0.992)$ & 2012 & This study \\
$0.576^{\mathrm{a}}(0.398-0.833)$ & $0.991(0.985-0.997)$ & $1986-1989$ & McAuley et al. 1996 \\
$0.166^{\mathrm{d}}(0.073-0.374)$ & $0.971(0.958-0.984)$ & $1976-1979$ & Dwyer et al. 1988 \\
$0.613^{\mathrm{c}}(0.274-0.885)$ & $0.992(0.979-0.998)$ & $1984-1985$ & Wiley and Causey 1987 \\
$0.833^{\mathrm{a}}(0.693-1.000)$ & $0.997(0.994-1.000)$ & $1982-1984$ & Derleth and Sepik 1990 \\
$0.114^{\mathrm{a}}(0.073-0.177)$ & $0.965(0.958-0.972)$ & $1986-1989$ & McAuley et al. 2010 \\
\hline
\end{tabular}

a Kaplan-Meier estimates. ${ }^{\mathrm{b}}$ Apparent survival, $95 \% \mathrm{CI}$ not available. ${ }^{\mathrm{c}}$ Mayfield method used, no variation reported. ${ }^{\mathrm{d}}$ Closed population mark-recapture model estimates. 
brood-rearing $=0.9964(95 \%$ CI: $0.9895-1.0034)$, and pre-migration $=0.9980(95 \% \mathrm{CI}: 0.9952-1.0008)]$. Breeding-season cumulative survival rate for adult females from 1 April - 30 June based on Kaplan-Meier estimates was 0.695 (95\% CI: $0.357-1.052)$ in 2011, 0.740 (95\% CI: 0.391 -1.090 ) in 2012, and 0.751 (95\% CI: $0.499-1.000$ ) for both years combined (Table 2).

Nest survival rate We monitored 52 woodcock nests (2011: $n=26,2012: n=26$ ) from 4 May to 11 June 2011 and from 9 April to 9 June 2012. We censored 4 nests from our analysis ( 1 in 2011 and 3 in 2012). Of the 45 nests we included in our analyses, eggs failed to hatch in $21(\sim 47 \%)$ and eggs that failed to hatch were either depredated (71\%) or abandoned by the female (29\%). Kaplan-Meier cumulative survival rate estimates for a 24-day laying and incubation period for nests were 0.455 (95\% CI: 0.297 - 0.696 ) in 2011 and 0.786 (95\% CI: $0.620-0.995)$ in 2012 (Table 2).

Juvenile survival rate From 16 May to 29 June 2011 and 20 April to 16 June 2012, we radio-marked 73 (2011: $n=22,2012: n=51$ ) juvenile woodcock from 51 broods (2011: $n=16,2012: n=35$ ). We assigned fates to 134 juvenile woodcock (2011: $n=$ 63, 2012: $n=71$ ), including fates of 49 marked and 85 unmarked juveniles from 47 broods (2011: $n=23$, 2012: $n=24$ ), resulting in an effective sample size of 859 observation intervals. We excluded data from 24 marked juvenile woodcock due to uncertainty regarding transmitter failure (i.e., we did not know if the transmitter failed or if the juvenile was depredated). Cumulative survival rate for juvenile woodcock based on Kaplan-Meier estimates for the 61-day period from 1 May - 30 June was 0.330 (95\% CI: 0.188 - 0.613 ) in 2011 and 0.576 (95\% CI: $0.398-0.833$ ) in 2012 (Table 2).

\section{SURVIVAL RATE MODELS}

Female survival rate Our best-supported model of adult female woodcock survival rate was the null model (Table 3), suggesting that female survival was relatively constant between 2011 and 2012. Although we constructed our base model to include YEAR to account for differences in survival between 2011 and 2012, survival was similar between years $\left(\beta_{2011}=\right.$ $-0.16,95 \%$ CI: -1.67 to 1.45$)$ and a null model that excluded year effects had a lower $\mathrm{AIC}_{\mathrm{c}}\left(\Delta \mathrm{AIC}_{\mathrm{c}}=1.94\right.$, Table 3$)$. No other covariates were related to survival of adult females. Models that included MINT, MAXT, and PCPT were within $2 \mathrm{AIC}_{\mathrm{c}}$ units of our best-supported model (Table 3); we considered these covariates to be uninformative, however, because they did not reduce $\mathrm{AIC}_{\mathrm{c}}$ relative to the simpler, higher-ranked model (Arnold 2010). Because there was no evidence to suggest that REPR was related to female woodcock survival rate (Table 3), we did not assess the relationship(s) between female survival rate and NEST and BROOD in post hoc analyses.

Nest survival rate Our best-supported model of nest survival rate included only YEAR, with no difference in survival rate between 2011 and $2012\left(\beta_{2011}=-0.768,95 \% \mathrm{CI}\right.$ : -1.70 to 0.166 , Table 4 ). Addition of other covariates did not result in competitive models (Table 4 ).

Juvenile survival rate Our best-supported model of juvenile woodcock survival rate included YEAR, JAGE, MINT, and PCPT (Table 5). In our best-supported model, $95 \%$ confidence intervals around coefficient estimates for YEAR $\left(\beta_{2011}=-0.85,95 \%\right.$ CI: -1.77 to 0.07$)$ and MINT

Table 3. Model-selection results and models of American woodcock adult female survival rate at Tamarac National Wildlife Refuge, Rochert, Minnesota, USA, in 2011 and 2012. Models consider reproductive status (REPR; prenesting, incubating, brood-rearing, or pre-migration), maximum and minimum temperature (MAXT and MINT), and precipitation (PCPT). Models were ranked according to the difference in Akaike's information criterion $\left(\triangle \mathrm{AIC}_{\mathrm{c}}\right.$; $\mathrm{AIC}_{\mathrm{c}}$ of top-ranked model $\left.=71.25\right)$ adjusted for sample size $(n=2,091$ intervals $)$ within steps. Akaike model weights $\left(\omega_{\mathrm{i}}\right)$ and number of estimable parameters $(\mathrm{K})$ are presented for each model. Null model includes only an intercept and no covariates and is presented as reference. Sequential model development started with an initial model including only a YEAR. Step 2 included the addition of the REPR covariate and Step 3 included the addition of weather-related covariates.

\begin{tabular}{|c|c|c|c|c|c|}
\hline Model step & Model & $\mathrm{AIC}_{\mathrm{c}}$ & $\Delta \mathrm{AIC}_{\mathrm{c}}$ & $\omega_{i}$ & $\mathbf{K}$ \\
\hline & Null & 71.21 & -- & -- & 1 \\
\hline Initial model & YEAR & 73.15 & -- & -- & 2 \\
\hline \multirow[t]{2}{*}{ Step 2} & YEAR $^{a}$ & 73.15 & 0.00 & 0.92 & 2 \\
\hline & YEAR+REPR & 78.06 & 4.91 & 0.08 & 6 \\
\hline \multirow[t]{8}{*}{ Step 3} & YEAR $^{b}$ & 73.15 & 0.00 & 0.29 & 2 \\
\hline & YEAR+MINT & 73.74 & 0.59 & 0.21 & 3 \\
\hline & YEAR+PCPT & 74.89 & 1.74 & 0.12 & 3 \\
\hline & YEAR+MAXT & 75.11 & 1.96 & 0.11 & 3 \\
\hline & YEAR+MINT+PCPT & 75.27 & 2.12 & 0.10 & 4 \\
\hline & YEAR+MAXT+MINT & 75.61 & 2.46 & 0.08 & 4 \\
\hline & YEAR+MAXT+PCPT & 76.64 & 3.49 & 0.05 & 4 \\
\hline & YEAR+MAXT+MINT+PCPT & 77.27 & 4.12 & 0.04 & 5 \\
\hline
\end{tabular}


$\left(\beta_{\text {MINT }}=0.14,95 \% \mathrm{CI}:-0.004\right.$ to 0.28$)$ included zero, indicating no statistically significant relationship with survival rate of juvenile woodcock (Table 5). JAGE ( $\beta_{\mathrm{AGE}}$ $=0.098,95 \%$ CI: 0.04 to 0.16$)$ was positively associated with juvenile survival rate and PCPT $\left(\beta_{\mathrm{PCPT}}=-0.20,95 \%\right.$ CI: -0.39 to -0.01 ) was negatively associated with juvenile survival rate. Daily survival rate of juvenile woodcock decreased approximately 0.007 for each additional $\mathrm{cm}$ of precipitation during the interval between subsequent locations. Juvenile daily survival rate increased approximately 0.002 for each additional day of age up to 15 days old.

We considered covariates related to vegetation structure in our post hoc analysis of juvenile survival rate. STEM was the only covariate related to vegetation characteristics to decrease $\mathrm{AIC}_{\mathrm{c}}$ when added to our best-supported model based on our sequential analysis (Table 6). STEM had a significant positive relationship with juvenile woodcock survival rate $\left(\beta_{\text {STEM }}=0.0001,95 \%\right.$ CI: 0.000 to $0.0003)$. Juvenile daily survival rate increased with stem density, resulting in a 0.006 increase in survival for every additional 10,000 stems/ha.

\section{Discussion}

Understanding the relationship(s) between BMPs applied at a demonstration-area scale and woodcock vital rates can help elucidate how the application of BMPs at this scale may affect local population dynamics and growth rates. Although female, juvenile, and nest survival rates have been estimated previously for woodcock, these estimates are limited to the eastern portion of their breeding range (e.g., Wiley and Causey 1987, Derleth and Sepik 1990, Krementz and Berdeen 1997, Longcore et al. 2000) and estimates of these vital rates are not available at the demonstration-area scale.

Our estimates of survival rates of females and nests were lower than those reported from other studies (Table 2; Mendall and Aldous 1943, Gregg 1984, Derleth and Sepik 1990, McAuley et al. 1996, Longcore et al. 200o) and our estimates of juvenile survival rate were similar to (Gregg 1984, Wiley and Causey 1987) or higher than survival rate estimates reported elsewhere (Table 2; Dwyer et al. 1988, McAuley et al. 2010). These previous studies also were conducted in areas where management for woodcock had been implemented. Woodcock are known to respond to vegetation management and select suitable
Table 4. Model-selection results and models of American woodcock nest survival rate at Tamarac National Wildlife Refuge, Rochert, Minnesota, USA, in 2011 and 2012. Models consider nest age (NAGE), nest initiation date (INIT), maximum and minimum temperature (MAXT and MINT), precipitation (PCPT), woody stem density (STEM), basal area (BAS), and distance to edge (EDGE). Models were ranked according to the difference in Akaike's information criterion $\left(\triangle \mathrm{AIC}_{c} ; \mathrm{AIC}_{\mathrm{c}}\right.$ of top-ranked model $\left.=140.51\right)$ adjusted for sample size $(n=548)$. Akaike model weights $\left(\omega_{\mathrm{i}}\right)$ and number of estimable parameters $(\mathrm{K})$ are also presented. Null model includes only an intercept and no covariates and is presented as reference. Sequential model development started with an initial model including only a YEAR covariate. Step 2 included the addition of AGE and INIT covariates, Step 3 included the addition of weather-related covariates, and Step 4 included the addition of vegetation structure covariates.

\begin{tabular}{|c|c|c|c|c|c|}
\hline Model step & Model & $\mathrm{AIC}_{\mathrm{c}}$ & $\Delta \mathrm{AIC}_{\mathrm{c}}$ & $\omega_{\mathrm{i}}$ & $\mathbf{K}$ \\
\hline & Null & 141.66 & -- & -- & 1 \\
\hline Initial model & YEAR & 140.95 & -- & -- & 2 \\
\hline \multirow[t]{4}{*}{ Step 2} & YEAR a $^{a}$ & 140.95 & 0.00 & 0.48 & 2 \\
\hline & YEAR+NAGE & 142.38 & 1.43 & 0.24 & 3 \\
\hline & YEAR+INIT & 142.81 & 1.86 & 0.19 & 3 \\
\hline & YEAR+NAGE+INIT & 144.29 & $3 \cdot 34$ & 0.09 & 4 \\
\hline \multirow[t]{8}{*}{ Step 3} & YEAR $^{a}$ & 140.95 & 0.00 & 0.27 & 2 \\
\hline & YEAR+MAXT & 141.88 & 0.93 & 0.17 & 3 \\
\hline & YEAR+MAXT+MINT & 142.33 & 1.38 & 0.13 & 4 \\
\hline & YEAR+MINT & 142.41 & 1.46 & 0.13 & 3 \\
\hline & YEAR+PCPT & 142.46 & 1.68 & 0.12 & 3 \\
\hline & $\mathrm{YEAR}+\mathrm{MAXT}+\mathrm{PCPT}$ & 143.74 & 2.79 & 0.07 & 4 \\
\hline & YEAR+MINT+PCPT & 143.82 & 2.87 & 0.06 & 4 \\
\hline & YEAR+MAXT+MINT+PCPT & 144.23 & 3.27 & 0.05 & 5 \\
\hline \multirow[t]{8}{*}{ Step 4} & YEAR $^{\mathrm{b}}$ & 140.95 & 0.00 & 0.29 & 2 \\
\hline & YEAR+STEM & 141.48 & 0.53 & 0.22 & 3 \\
\hline & YEAR+EDGE & 142.86 & 1.91 & 0.11 & 3 \\
\hline & YEAR+BAS & 142.93 & 1.98 & 0.11 & 3 \\
\hline & YEAR+STEM+EDGE & 143.06 & 2.11 & 0.10 & 4 \\
\hline & YEAR+STEM+BAS & $143 \cdot 34$ & 2.39 & 0.09 & 4 \\
\hline & YEAR+BAS+EDGE & 144.86 & $3 \cdot 91$ & 0.04 & 4 \\
\hline & YEAR+STEM+BAS+EDGE & 144.94 & 3.99 & 0.04 & 5 \\
\hline $\begin{array}{l}\text { a Indicates best- } \\
\text { b Indicates best- }\end{array}$ & $\begin{array}{l}\text { pported model for each step, model mo } \\
\text { pported overall model; } \mathrm{AIC}_{\mathrm{c}} \text { of top-ranl }\end{array}$ & on to $n$ & $\begin{array}{l}\text { step in an } \\
40.95 \text {. }\end{array}$ & alysis. & \\
\hline
\end{tabular}


managed areas for courtship, nesting, and brood-rearing (Dwyer et al. 1988, McAuley et al. 1996). Breeding woodcock are also known to select for a narrow range of vegetation structure and composition (McAuley et al. 1996). We did not observe any evidence of relationships between survival rates of nests and vegetation characteristics; we did, however, observe a slight positive relationship between juvenile survival rate and woody stem density. We likely had difficulty detecting relationships between survival rates and vegetation characteristics created by application of BMPs because female woodcock selected for a narrow range of vegetation characteristics for diurnal cover, nesting, and brood rearing.

\section{FEMALE SURVIVAL RATE}

No covariates included in our analysis were associated with female woodcock survival rate, suggesting that female survival rate did not differ between years, with reproductive status, or in relation to the environmental conditions we observed. In contrast, Longcore et al. (2000) reported that survival rate of female woodcock breeding in Maine varied among years during the 4 -year course of their study on an area that was managed for woodcock. Longcore et al. (200o) estimated mean female survival rate during the breeding season (1 April to 15 June) to be 0.810 for second-year females (females known to be in the second calendar year of life), and 0.815 for aftersecond-year females (females known to be in their third or later calendar year of life) in a similar radio-telemetry study in Maine. Derleth and Sepik (1990) reported post-breeding season (15 June - 20 October) survival rate of adult females ranged from 0.88 to 0.90 . Our breeding-season survival rate estimates generally were lower than those reported by Longcore et al. (2000) for the same 76 -day period (1 April to 15 June), and lower than their 4 -year mean of 0.826 , suggest- ing that females in the western portion of the breeding range of woodcock may survive at lower rates during the breeding season. However, some breeding-season survival rate estimates for years reported by Longcore et al. (2000) were similar to our estimates (Table 2), suggesting that adult female woodcock survival rate is variable among breeding seasons.

Inter-year variation in survival rate has been observed in woodcock in both the breeding season and during fall (Longcore et al. 200o, Bruggink et al. 2013). Longcore et al. (2000) attributed inter-year differences in survival rate to 1 year with lower female survival rate due to an extended period of nesting. We observed no relationship between reproductive status of females and survival rate (although

Table 5. Model-selection results and models of juvenile American woodcock survival rate at Tamarac National Wildlife Refuge, Rochert, Minnesota, USA, in 2011 and 2012. Models consider juvenile age (JAGE), hatch date (HD), maximum and minimum temperature (MAXT and MINT), precipitation (PCPT), woody stem density (STEM), basal area (BAS), and distance to edge (EDGE). Models were ranked according to the difference in Akaike's information criterion $\left(\triangle \mathrm{AIC}_{\mathrm{c}} ; \mathrm{AIC}_{\mathrm{c}}\right.$ of top-ranked model $=235 \cdot 60)$ adjusted for sample size $(n=1,754)$. Akaike model weights $\left(\omega_{\mathrm{i}}\right)$ and number of estimable parameters $(\mathrm{K})$ are also presented. Null model includes only an intercept and no covariates and is presented as reference. Sequential model development started with an initial model including only a YEAR covariate. Step 2 included the addition of AGE and HD covariates, and Step 3 included the addition of weather-related covariates.

\begin{tabular}{|c|c|c|c|c|c|}
\hline Model step & Model & $\mathrm{AIC}_{\mathrm{c}}$ & $\Delta \mathrm{AIC}_{\mathrm{c}}$ & $\omega_{i}$ & $\mathbf{K}$ \\
\hline & Null & 245.59 & -- & -- & 1 \\
\hline Initial model & YEAR & 247.10 & -- & -- & 2 \\
\hline \multirow[t]{8}{*}{ Step 2} & $\mathrm{YEAR}+J A G E^{\text {a }}$ & 238.83 & 0.00 & 0.54 & 3 \\
\hline & YEAR+JAGE+HD & 240.76 & 1.93 & 0.20 & 4 \\
\hline & YEAR+JAGE+HD+(HD×YEAR $)$ & 241.87 & 3.04 & 0.12 & 6 \\
\hline & YEAR+JAGE+(HD×YEAR) & 241.86 & 3.04 & 0.12 & 5 \\
\hline & YEAR & 247.10 & 8.27 & 0.01 & 2 \\
\hline & YEAR+HD & 248.04 & 9.22 & 0.01 & 3 \\
\hline & YEAR+HD+(HD×YEAR) & 248.15 & 9.32 & 0.01 & 5 \\
\hline & YEAR+( HD×YEAR $)$ & 248.15 & 9.32 & 0.01 & 4 \\
\hline \multirow[t]{8}{*}{ Step 3} & YEAR+JAGE+MINT+PCPT b & 235.03 & 0.00 & 0.28 & 5 \\
\hline & YEAR+JAGE+MAXT+MINT+PCPT & 235.57 & 0.54 & 0.21 & 6 \\
\hline & YEAR+JAGE+MAXT+PCPT & 236.22 & 1.19 & 0.15 & 5 \\
\hline & YEAR+JAGE+PCPT & 236.81 & 1.78 & 0.11 & 4 \\
\hline & YEAR+JAGE+MINT & 236.85 & 1.82 & 0.11 & 4 \\
\hline & YEAR+MAXT+ +MINT & 238.22 & 3.19 & 0.06 & 5 \\
\hline & YEAR+JAGE & 238.83 & 3.80 & 0.04 & 3 \\
\hline & YEAR+MAXT & 239.38 & 4.35 & 0.03 & 4 \\
\hline
\end{tabular}


we acknowledge that in our study, our power to detect differences among reproductive status categories was likely low), which suggests females may not be more vulnerable during nesting as speculated by Longcore et al. (2000) and reported for other ground-nesting species (e.g., Brasher et al. 2006). Female woodcock may be vulnerable to predation at a similar rate independent of their reproductive status due to their cryptic nature and relatively high mobility (Derleth and Sepik 1990).

Temperature and precipitation conditions varied considerably throughout our study; we did not, however, observe a relationship between female survival rate and minimum or maximum temperatures or precipitation. Longcore et al. (2000) found no relation between survival rate and minimum temperature in the spring. Females also may delay or reduce energetically costly behaviors (e.g., egg-laying and incubation) in spring if weather conditions are adverse or food availability is low, allowing for high survival rate of females during the spring (Rabe et al. 1983, Longcore et al. 2000). Females likely are able to withstand consistent temperatures below freezing because of their relatively large body size and associated increased thermoregulatory ability to conserve heat (Mendall and Aldous 1943, Longcore et al. 2000).

We did not assess the relationship between adult female survival rate and vegetation characteristics during the breeding season because our vegetation data were recorded only when females were associated with a nest or brood. Because few radio-marked female woodcock in our study died, our estimates of breeding-season survival rate were relatively high for both years, which constrained our ability to assess relationships between habitat characteristics and adult female survival rate. However, at less-fine categories [e.g., hardwoods, conifers, and alder (Alnus spp.)] of forest cover types in Maine, Longcore et al. (2000) detected survival rate differences of adult female woodcock among cover types.

\section{NEST SURVIVAL RATE}

We found no relationships between year, initiation date, weather, or vegetation characteristics and survival rate of woodcock nests. Considerable differences can occur in nest-site selection when females return to breeding areas in spring, and snow depth likely influences availability of nest sites (Sepik et al. 1989, McAuley et al. 1990). Spring phenology (e.g., leafout timing) was much earlier in 2011 than
2012 on our study site, and snow depths in 2011 were substantially higher than in 2012 early in the nesting period.

We also suspect that difference in snow depth between 2011 and 2012 affected the timing of nesting; the mean initiation date in 2011 was 3 May ( $\mathrm{SE}=2.3$ days) and in 2012 was 19 April ( $\mathrm{SE}=3.6$ days). Roboski and Causey (1981) and Dwyer et al. (1988) also found nest initiation dates differed between years and suggested local weather conditions as the cause. In Missouri, Murphy and Thompson (1993) observed nest initiation peak when male displaying activity was highest, which also could be delayed if unfavorable weather conditions are present. Therefore, female woodcock likely are taking advantage of favorable weather conditions to nest, as suggested by Whiting (2006). If nest-site selection is dependent on early spring snow conditions, vegetation characteristics around nest sites are likely to vary among years. Our results indicated nest-site selection differed between years at our study site. Basal area was higher around nest locations in 2012, perhaps because lower snow depth that year made areas farther from edges and with more mature trees available for nesting. Although distance to edge may have been farther in 2011 than 2012, this may have been an artifact of our sample of females. In 2011, we captured a higher proportion of females prior to nesting than we did in 2012. In
Table 6. Model-selection results and models from post hoc analysis assessing the relationship of juvenile American woodcock survival rate and habitat covariates at Tamarac National Wildlife Refuge, Rochert, Minnesota, USA, in 2011 and 2012. Models consider juvenile age (JAGE), minimum temperature (MINT), precipitation (PCPT), woody stem density (STEM), basal area (BAS), and distance to edge (EDGE). We assessed our best-supported model from sequential analysis of juvenile survival (see text for explanation) and added all combinations of vegetation structure covariates to this best-supported model. Models were ranked according to the difference in Akaike's information criterion $\left(\Delta \mathrm{AIC}_{\mathrm{c}} ; \mathrm{AIC}_{\mathrm{c}}\right.$ of top-ranked model $\left.=87.52\right)$ adjusted for sample size $(n=$ 420 ); Akaike model weights $\left(\omega_{\mathrm{i}}\right)$ and number of estimable parameters $(\mathrm{K})$ are also presented.

\begin{tabular}{|c|c|c|c|}
\hline Model & $\Delta \mathrm{AIC}_{\mathrm{c}}$ & $\omega_{i}$ & $\mathbf{K}$ \\
\hline YEAR+JAGE+MINT+PCPT+STEM ${ }^{\mathrm{a}}$ & 0.00 & 0.38 & 6 \\
\hline YEAR+JAGE+MINT+PCPT & 1.90 & 0.15 & 5 \\
\hline YEAR+JAGE+MINT+PCPT+STEM+BAS & 1.93 & 0.14 & 7 \\
\hline YEAR+JAGE+MINT+PCPT+STEM+EDGE & 2.06 & 0.13 & 7 \\
\hline YEAR+JAGE+MINT+PCPT+EDGE & 3.28 & 0.07 & 6 \\
\hline YEAR+JAGE+MINT+PCPT+BAS & 3.89 & 0.05 & 6 \\
\hline YEAR+JAGE+MINT+PCPT+STEM+BAS+EDGE & 4.01 & 0.05 & 8 \\
\hline YEAR+JAGE+MINT+PCPT+EDGE+BAS & 3.99 & 0.02 & 7 \\
\hline
\end{tabular}


2012, we captured more females when they were already associated with a nest that we found by searching along edges with dogs, perhaps biasing our sample in that year to nests closer to edges (e.g., Peterson et al. 2015). We found no difference in woody stem densities between years, which suggests that woodcock selected for high woody stem densities independent of other nesting vegetation characteristics.

Woodcock select for nest sites with relatively low basal area and high woody stem density (McAuley et al. 1996). Woody stem density around nests in our study was similar to that in Maine (McAuley et al. 1996, also based on radio telemetry), where woody stem density was high $(\bar{x}=13,919$ stems/ha, $\mathrm{SE}=1,688)$. Nest sites we found in 2011 had similar basal area as nest sites in Maine $\left(\bar{x}=9.5 \mathrm{~m}^{2} /\right.$ ha, $\mathrm{SE}=1.0$, McAuley et al. 1996); however, nest sites in 2012 had higher basal area than those in 2011 and than those reported by McAuley et al. (1996) in Maine. Our 2012 estimate of basal area surrounding nest sites is the highest reported to date (McAuley et al. 1996), which may have been due to the unseasonably early spring. Under the conditions we observed in 2012, woodcock may have selected more mature forest cover types for nesting if those areas had less snow and therefore afforded more available nest sites. Murphy and Thompson (1993) measured stem densities, basal area, and distance from field in a study of woodcock nest sites in Missouri; their average stem density and distance to field were considerably lower than our average stem density and distance to edge, but their estimates of basal area were similar to ours. The difference in these measurements could be due to a bias in their study because they only searched along edges to locate nests (Murphy and Thompson 1993).

Our apparent nest survival rate for both years combined (0.56) was similar to the apparent survival rate of 0.59 reported by McAuley et al. (1996), 0.62 reported by Mendall and Aldous (1943), and 0.26 - 0.51 reported by Gregg (1984) using Mayfield's method (Mayfield 1961). Although we found no evidence that inclement weather or nest initiation date was related to nest survival rate, a late-season snow storm occurred on 7-8 May 2011 and resulted in many nests being abandoned, suggesting extreme weather events may cause lower nest survival rate in woodcock. A later nest initiation date in 2011 also may have affected nest survival rate; we may, however, have been unable to detect these relationships because we included year as a covariate in our analysis and year may be correlated with other covariates. Similar to results reported by McAuley et al. (1996), we found no evidence that vegetation characteristics around nest sites influenced nest survival rate (Table 4). Across their breeding range, woodcock select nest sites with high stem density (McAuley et al. 1996), and we also observed high and similar stem density at both failed and successful nests.

\section{JUVENILE SURVIVAL RATE}

Total interval precipitation (PCPT) was the only covariate that showed a statistically significant relationship with juvenile woodcock survival rate. Precipitation, especially high precipitation within an interval, was negatively related to juvenile woodcock survival rate. Sheldon (1971) and Owen (1977) suggested that periods of adverse weather (i.e., precipitation) can cause significant mortality in juvenile woodcock. Dwyer et al. (1988) reported finding a significant negative relationship between precipitation and juvenile production; this relationship also has been suggested in other precocial birds (e.g., Pietz et al. 2003, Brundey et al. 2013). Rabe et al. (1983) suggested that due to growth requirements of juvenile woodcock, weather-related stress has the greatest potential to limit survival rate of juveniles during the brood-rearing period.

Although juvenile age (JAGE) and minimum temperatures (MINT) did not exhibit a statistically significant relationship with survival rate in our best-supported model, in initial steps in our modeling of juvenile survival rate, JAGE was positively related to survival rate, suggesting that survival rate increased with juvenile age. As juveniles age, they are better able to thermoregulate (Rabe et al. 1983) and may therefore better survive periods of inclement weather, and they also are better able to escape predators as they gain the ability to fly. This is contrary to what Wiley and Causey (1987) estimated in Alabama, where juvenile woodcock had a higher survival rate prior to fledging ( $<15$ days), and were most vulnerable between fledging and brood break-up (15 to 32 days). However, they also suggested that this may have been due to their research methods, which may have negatively influenced juvenile survival rate (in contrast, we found no evidence for an effect of transmitters on survival; Daly et al. 2015). In contrast to our results, Wiley and Causey (1987) reported no apparent effects of weather on juvenile woodcock survival rate. McAuley et al. (2010) however, found a positive relationship between juvenile survival rate and minimum temperature in Maine, similar to our observations. Juvenile woodcock in northern parts of the breeding range (e.g., Minnesota and Maine) may be more likely to be physiologically stressed from exposure to cold and wet weather than juveniles in southern portions of their breeding range (e.g., Alabama). However, it was difficult for us to determine proximate cause of death of many radio-marked juveniles (e.g., predation versus exposure and subsequent consumption by a predator); therefore, it was not apparent whether or how predation and weather may have interacted to affect juvenile woodcock survival rate in our study. We also were unable to determine the cause of death of unmarked juvenile woodcock.

Previous studies of woodcock survival rate were concentrated in the eastern portion of the woodcock breeding range on landscapes where young forest cover was an 
emphasis of management, and in general, published estimates of survival rate are higher than our estimates. Adult female survival rate was constant between years and under the environmental conditions experienced in our study, but nest and juvenile survival rates differed between years. Similar to recent studies of songbird productivity (Streby and Andersen 2011) that considered juvenile survival, our results suggest that juvenile survival rate from hatch to independence from adult care, and factors related to juvenile survival rate, may contribute more to woodcock population dynamics than adult survival.

\section{Management Implications}

Our results suggest that adult female woodcock select nesting sites and raise broods in cover types with similar structural characteristics (e.g., high woody stem density). Cover types with high woody stem density are thought to be selected by woodcock to provide cover from predators and shelter from inclement weather. Inclement weather (e.g., precipitation, cold temperatures) during the nesting and brood rearing periods likely has negative impacts on woodcock seasonal productivity and subsequent recruitment. Weather conditions between our field seasons varied greatly, and likely resulted in lower seasonal productivity in 2011 than 2012. BMPs established for woodcock include management of landscapes to provide diverse stages of young forests, providing woodcock with cover that may mitigate mortality during critical biological periods. Precipitation and severe weather events are projected to increase during the spring when woodcock are nesting and rearing broods (International Panel on Climate Change 2014). Providing high-quality nesting and brood-rearing habitat for woodcock during spring that mitigate the potential negative effects of weather conditions on nest and juvenile survival rates is likely critical to managing landscapes that will support woodcock populations.

\section{Acknowledgments}

We thank J. Nelson, M. Johnson, D. Page, and J. Lehman for their long hours assisting in capturing, radio marking, and tracking woodcock. We especially are grateful to D. Dustin and E. Johnson for volunteering many hours running dogs through the woods to find woodcock nests and broods; D. McAuley for his valuable insights on capture methods; H. Streby, J. Fieberg, G. Kramer, and T. Arnold for assistance with analytical techniques; and 2 anonymous reviewers whose comments helped improve our manuscript. We thank Tamarac National Wildlife Refuge staff for access to refuge lands, and for equipment, lodging, and logistical support. Use of trade, firm, or product names is for descriptive purposes only and does not imply endorsement by the U.S. Government, the University of Minnesota, or the State of Minnesota. The findings and conclusions in this article are those of the author(s) and do not necessarily represent the views of the U.S. Fish and Wildlife Service. The authors of this manuscript report that they have no potential sources of conflict of interest that might be perceived as influencing the authors' objectivity. This project was funded by the U.S. Fish and Wildlife Service Webless Migratory Game Program through Research Work Order No. 91 at the U.S. Geological Survey Minnesota Cooperative Fish and Wildlife Research Unit, with additional funding provided by Woodcock Minnesota.

\section{Literature Cited}

Ammann, G.A. 1974. Methods of capturing American woodcock broods. Pages 593-605 in S. Lundstrom, editor. Eleventh International Congress of Game Biologists. Stockholm, Sweden.

Ammann, G.A. 1977. Finding and banding woodcock broods using pointing dogs. Michigan Department of Natural Resources, Wildlife Division Report 2780.

Ammann, G.A. 1982. Age determination of American woodcock chicks by bill length. Pages 22-25 in T.J. Dwyer and G.L. Storm, technical coordinators. Woodcock ecology and management. U.S. Fish Wildlife Service, Wildlife Resource Report 14.

Amundson, C.L., and T.W. Arnold. 2010. Effects of radiotransmitters and plasticine bands on mallard duckling survival. Journal of Field Ornithology 81:310-316.

Arnold, T.W. 2010. Uninformative parameters and model selection using Akaike's information criterion. Journal of Wildlife Management 74:1175-1178.

Arnold.T.W., E.A. Roche, J.H. Devries, and D.W. Howerter. 2012. Cost of reproduction in breeding female mallards: predation risk during incubation drives annual mortality. Avian Conservation and Ecology 7:1.

Avery T.E., and H.E. Burkhart. 2002. Forest measurements. 5th edition. McGraw-Hill, New York, New York, USA.

Blums P., J.D. Nichols, J.E. Hines, M.S. Lindberg, and A. Mednis. 2005. Individual quality, survival variation and patterns of phenotypic selection on body condition and timing of nesting in birds. Oecologia 143:365-376.

Brasher, M.G., T.W. Arnold, J.H. Devries, and R.M. Kaminski. 2006. Breeding-season survival of male and female mallards in Canada's Prairie-Parklands. Journal of Wildlife Management 70:805-811.

Bruggink, J.G., E.J. Oppelt, K.E. Doherty, D.E. Andersen, J. Meunier, and R.S. Lutz. 2013. Fall Survival of American woodcock in the western Great Lakes region. Journal of Wildlife Management 77:1021-1030.

Brundey, L.J., T.W. Arnold, S.P. Saunders, and F.J. Cuthbert. 2013. Survival of piping plover (Charadrius melodus) chicks in the Great Lakes region. Auk 130:150-16o.

Burnham, K.P., and D.R. Anderson. 2002. Model selection and multimodel inference: a practical information-theoretic approach. Second Addition. Springer-Verlag, New York, New York, USA.

Chalfoun A.D., F.R. Thompson III, and M.J. Ratnaswamy. 2002. Nest predators and fragmentation: a review and meta-analysis. Conservation Biology 16:306-318.

Chouinard M.P., Jr., and T.W. Arnold. 2007. Survival and habitat use of mallard (Anas platyrhynchos) broods in the San Joaquin Valley, California. Auk 124:1305-1316.

Daly, K.O., D.E. Andersen, W.L. Brininger, and T.R. Cooper. 2015. Radio-transmitters have no impact on survival of pre-fledged American woodcocks. Journal of Field Ornithology 86:345-351.

Derleth, E.L., and G.F. Sepik. 1990. Summer-fall survival of American woodcock in Maine. Journal of Wildlife Management 54:97-106. 
Dessecker, D.R., and D.G. McAuley. 2001. Importance of early successional habitat to ruffed grouse and American woodcock. Wildlife Society Bulletin 29:156-165.

Dwyer, T.J., G.F. Sepik, E.L. Derleth, and D.G. McAuley. 1988. Demographic characteristics of a Maine woodcock population and effects of habitat management. U.S. Fish and Wildlife Service, Fish Wildlife Resource Report 4, Washington D.C., USA.

ESRI. 2011. ArcGIS Desktop: Release 10. Environmental Systems Research Institute, Redlands, California, USA.

Gregg, L. 1984. Population ecology of woodcock in Wisconsin. Wisconsin Department of Natural Resources, Technical Bulletin 144 Madison, Wisconsin, USA.

International Panel on Climate Change (IPCC). 2014. Climate Change 2014: Impacts,

Adaptation, and Vulnerability. Cambridge University Press, Cambridge, UK.

James, F.C., and H.H. Shugart. 1970. A quantitative method of habitat description. Audubon Field Notes 24:727-736.

Johnson, D.H. 1979. Estimating nest success: the Mayfield method and an alternative. Auk 96: 651-661.

Kelley, J.R., S.J. Williamson, and T.R. Cooper (editors). 2008. American Woodcock Conservation Plan: a summary of and recommendations for woodcock conservation in North America. Wildlife Management Institute, Washington, D.C., USA.

Korschgen, C.E., K.P. Kenow, W.L. Green, D.H. Johnson, M.D. Samuel, L. Sileo. 1996. Survival of radiomarked canvasback ducklings in northwestern Minnesota. Journal of Wildlife Management 60:120-132.

Krementz, D.G., and J.B. Berdeen. 1997. Survival rates of American woodcock wintering in the Georgia Piedmont. Journal of Wildlife Management 61:1328-1332.

Lariviére, S. 2003. Edge effects, predator movements, and the travel-lane paradox. Wildlife Society Bulletin 31:315-320.

Longcore, J.R., D.G. McAuley, G.F. Sepik, and G.W. Pendleton. 2000. Survival of female American woodcock breeding in Maine. Pages 65-76 in D.G. McAuley, J.G. Bruggink, and G.F. Sepik, editors. Proceedings of the Ninth American Woodcock Symposium, U.S. Geological Survey, Information and Technology Report 2000ooog, Laurel, Maryland, USA.

Manolis, J.C., D.E. Andersen, and F.J. Cuthbert. 2002. Edge effect on nesting success of ground nesting birds near regenerating clearcuts in a forest-dominated landscape. Auk 119:955-970.

Martin, F.W. 1964. Woodcock age and sex determination from wings. Journal of Wildlife Management 28:287-293.

Mayfield, H. 1961. Nesting success calculated from exposure. Wilson Bulletin 73:255-261.

McAuley, D.G., J.R. Longcore, D.A. Clugston, R.B. Allen, A. Weik, S. Williamson, J. Dunn, B. Palmer, K. Evans, W. Staats, G.F. Sepik, and W. Halteman. 2005. Effects of hunting on survival of American woodcock in the Northeast. Journal of Wildlife Management 69:1565-1577.

McAuley, D.G., J.R. Longcore, D.A. Clugston, W. Haltman, and G.F. Sepik. 2010. Survival of American woodcock broods and chicks in Maine. Pages 175-184 in C.A. Stewart and V.R. Frawley. editors. Proceedings of the Tenth American Woodcock Symposium, Michigan Department of Natural Resources and Environment, Lansing, Michigan, USA.

McAuley, D.G., J.R. Longcore, and G.F. Sepik. 199o. Renesting by American woodcocks (Scolopax minor) in Maine. Auk 107:407-410.

McAuley, D.G., J.R. Longcore, and G.F. Sepik. 1993a. Methods of woodcock research: experiences and recommendations. Pages 5-11 in J.R. Longcore and G.F. Sepik, editors. Eighth American Woodcock Symposium. U.S. Fish and Wildlife Service, Wildlife Resource Report 16, Washington D.C., USA

McAuley, D.G., J.R. Longcore, and G.F. Sepik. 1993b. Behavior of radio-marked breeding American woodcocks. Pages 116-125 in
J.R. Longcore and G.F. Sepik, editors. Eighth American Woodcock Symposium. U.S. Fish and Wildlife Service, Wildlife Resource Report 16, Washington D.C., USA.

McAuley, D.G., J.R. Longcore, G.F. Sepik, and G.W. Pendleton. 1996. Habitat characteristics of American woodcock nest sites on a managed area in Maine. Journal of Wildlife Management 60:138-148.

Mendall, H.L. 1938. A technique for banding woodcock. Bird-Banding 9:153-155.

Mendall, H.L., and C.M. Aldous. 1943. The ecology and management of the American woodcock. Maine Cooperative Wildlife Research Unit, University of Maine, Orono. 201 pp.

Murphy, D.W., and F.R. Thompson III. 1993. Breeding chronology and habitat of the American woodcock in Missouri. Pages 12-18 in J.R. Longcore and G.F. Sepik, editors. Eighth American Woodcock Symposium. U.S. Fish and Wildlife Service, Wildlife Resource Report 16, Washington D.C., USA.

Newlon, K.R., and V.A. Saab. 2011. Nest-site selection and nest survival of Lewis' woodpecker in aspen riparian woodlands. Condor 113:183-193.

Owen, R.B., Jr. 1977. American woodcock (Philohela minor $=$ Scolopax minor of Edwards of 1974). Pages 149-186 in G.C. Sanderson, editor. Management of migratory shore and upland game birds in North America. Int. Association of Fish and Wildlife Agencies, Washington, D.C., USA.

Peterson, S.M., H.M. Streby, J.A. Lehman, G.R. Kramer, A.C. Fish, and D.E. Andersen. 2015. High-tech or field techs: radio-telemetry is a cost-effective method for reducing bias in songbird nest searching. The Condor: Ornithological Applications 117: 386-395.

Pietz, P.J., G.L. Krapu, D.A. Brandt, and R.R. Cox, Jr. 2003. Factors affecting gadwall brood and duckling survival in prairie pothole landscapes. Journal of Wildlife Management 67:564-575.

Pollock, K.H., S.R. Winterstein, C.M. Bunck, and P.D. Curtis. 1989. Survival analysis in telemetry studies: the staggered entry design. Journal of Wildlife Management 53:7-15.

Rabe, D.L., H.H. Prince, and E.D. Goodman. 1983. The effect of weather on bioenergetics of American woodcock. Journal of Wildlife Management 47:762-771.

Roboski, J.C., and M.K. Causey. 1981. Incidence, habitat use, and chronology of woodcock nesting in Alabama. Journal of Wildlife Management 45:793-797.

Sauer, J.R., and J.B. Bortner. 1991. Population trends from the American Woodcock Singing-ground Survey, 1970-88. Journal of Wildlife Management 55:300-312.

Seamans, M.E., and R.D. Rau. 2016. American woodcock population status, 2016. U.S. Fish and Wildlife Service, Laurel, Maryland. $17 \mathrm{pp}$.

Sepik, G.F. 1994. A woodcock in the hand. Ruffed Grouse Society, Coraopolis, Pennsylvania, USA.

Sepik, G.R., and T.J. Dwyer. 1982. Woodcock response to habitat management in Maine. Pages 106-113 in T.J. Dwyer and G.L. Storm, editors. Woodcock ecology and management. U.S. Fish and Wildlife Service Research Report 14, Washington D.C., USA.

Sepik, G.F., W.H. Goudy, and D.R. Dessecker. 200o. Factors influencing recruitment and condition of American woodcock in Minnesota. Pages 65-76 in D.G. McAuley, J.G. Bruggink, and G.F. Sepik, editors. Proceedings of the Ninth American Woodcock Symposium, United States Geological Survey, Information and Technology Report 2000-0009, Laurel, Maryland, USA.

Sepik, G.F., D.G. McAuley, J.R. Longcore, and E.L. Derleth. 1989. Habitat requirements and management of woodcock in the Northeast: assessment of knowledge and needs. Pages 97-109 in J.C. Finley and M.C. Brittingham, editors. Timber management and its effects of wildlife. Proceedings of the 1989 Pennsylvania State Forest Resource Issues Conference. Pennsylvania State University, University Park, Pennsylvania, USA. 


\section{Breeding Season Survival of Woodcock $\cdot$ Daly et al.}

Shaffer, T.L. 2004. A unified approach to analyzing nest success. Auk 121:526-540.

Sheldon, W.G. 1971. The book of the American woodcock. University of Massachusetts Press, Amherst, Massachusetts, USA.

Streby, H.M., and D.E. Andersen. 2011. Seasonal productivity in a population of migratory songbirds: why nest data are not enough. Ecosphere 2: Article 78.

Streby, H.M., and D.E. Andersen. 2013. Survival of fledgling ovenbirds: influences of habitat characteristics at multiple spatial scales. Condor 115:403-410.

Vander Haegen, W.M. 1992. Bioenergetics of American woodcock during the breeding season on Moosehorn National Wildlife Refuge in Maine. Dissertation, University of Maine, Orono, Maine, USA.

Vander Haegen, W.M., W.B. Krohn, and R.B. Owen, Jr. 1993. Effects of weather on earthworm abundance and foods of American woodcock in spring. Pages 26-31 in J.R. Longcore and G.F. Sepik, editors. Proceedings of the Eighth American Woodcock Symposium, U.S. Fish and Wildlife Service Biological Report 16, Washington, D.C., USA.
Whiting Jr., R.M. 2006. American woodcock singing-ground surveys: should they be expanded? Pages 153-159 in C.A. Stewart and V.R. Frawley. editors. Proceedings of the Tenth American Woodcock Symposium, Michigan Department of Natural Resources and Environment, Lansing, Michigan, USA.

Wildlife Management Institute. 2009. Best Management Practices for woodcock and associated bird species: Upper Great Lakes Woodcock and Young Forest Initiative. Wildlife Management Institute. <https://youngforest.org/sites/default/files/research_ documents/Woodcock\%20 BMPs_Upper\%20Great\%2oLakes. pdf > Date visited: 39 March, 2017

Wildlife Management Institute. 2010. Implementing the American woodcock conservation plan: progress to date. Wildlife Management Institute, Washington D.C., USA.

Wiley, E.N., II, and M.K. Causey. 1987. Survival of American woodcock chicks in Alabama. Journal of Wildlife Management 51:583-586.

Winterstein, S.R. 1992. Chi-square tests for intrabrood independence when using the Mayfield Method. Journal of Wildlife Management 58:398-401. 
Appendix I. Covariates used in logistic-exposure analysis of survival rates of American woodcock females, juveniles, and nests at Tamarac National Wildlife Refuge, Minnesota, USA, in 2011 and 2012, symbol, model(s) in which each covariate was included, and explanation of expected relationship between covariate and survival rate.

\begin{tabular}{|c|c|}
\hline \multicolumn{2}{|c|}{ Covariate / Symbol / Model(s) } \\
\hline $\begin{array}{l}\text { Basal area } \\
\text { BAS } \\
\text { Nest \& Juvenile }\end{array}$ & $\begin{array}{l}\text { Woodcock choose areas with relatively low basal area (Sepik and Dwyer 1982, McAuley et al. } 1996 \text {, } \\
\text { Dessecker and McAuley 2001). Areas with greater basal area provide a greater number of perches for } \\
\text { raptors and therefore we hypothesize basal area to have a negative relationship with juvenile and nest } \\
\text { survival rates. }\end{array}$ \\
\hline $\begin{array}{l}\text { Distance to edge } \\
\text { EDGE } \\
\text { Nest \& Juvenile }\end{array}$ & $\begin{array}{l}\text { It is a common assertion that edges provide travel corridors for mammalian, avian, and reptilian } \\
\text { predators, although empirical evidence is lacking or contradicting (Chalfoun et al. 2002, Lariviére } \\
\text { 2003). However, nest survival rates of ground nesting birds have been shown to decrease around } \\
\text { edges (Manolis et al. 2002). We hypothesized that survival rate of nests would be positively related } \\
\text { to distance to an edge (Gregg 1984, Manolis et al. 2002) and made the same hypothesis for juvenile } \\
\text { woodcock survival rate (Gregg 1984). }\end{array}$ \\
\hline $\begin{array}{l}\text { Hatch date } \\
\text { HD } \\
\text { Juvenile }\end{array}$ & $\begin{array}{l}\text { Juveniles that hatch earlier are more likely to be from the females in the best condition (Blums et al. } \\
\text { 2005); therefore we hypothesized that hatch date is negatively associated with juvenile survival rate. }\end{array}$ \\
\hline $\begin{array}{l}\text { Initiation date } \\
\text { INIT } \\
\text { Nest }\end{array}$ & $\begin{array}{l}\text { Nests initiated earlier in the season experience higher survival rates than nests initiated later for } \\
\text { many species (Newlon and Saab 2011); therefore, we hypothesized nest initiation date to have a } \\
\text { negative relationship with nest survival rate. }\end{array}$ \\
\hline $\begin{array}{l}\text { Juvenile age } \\
\text { JAGE } \\
\text { Juvenile }\end{array}$ & $\begin{array}{l}\text { Survival rate likely asymptotically increases with age of the juvenile because they are better able to } \\
\text { thermoregulate as they age (Rabe et al. 1983) and likely most vulnerable to predation soon after } \\
\text { leaving the nest (Streby and Andersen 2013); therefore, we hypothesized a positive relationship with } \\
\text { age and juvenile survival rate. }\end{array}$ \\
\hline $\begin{array}{l}\text { Maximum } \\
\text { temperature } \\
\text { MAXT } \\
\text { Female, Nest, } \\
\text { and Juvenile }\end{array}$ & $\begin{array}{l}\text { We predicted that maximum temperature would be positively related to survival rate of females in } \\
\text { the spring and was likely positively related to survival rates of nests and juveniles, especially early } \\
\text { after egg laying or hatching. During the breeding season, energetic demands are high for female } \\
\text { woodcock (Rabe et al. 1983), especially during egg laying, incubation, and brood rearing. Higher } \\
\text { maximum temperatures likely increase survival rate of females during incubation and brood } \\
\text { rearing (Rabe et al. 1983, Longcore et al. 2000). Females are also more active at higher ambient air } \\
\text { temperatures (Vander Haegen 1992) and females will brood juveniles when temperatures are low } \\
\text { (McAuley et al. 2010); therefore, at higher temperatures females likely spend more of their time } \\
\text { foraging and are more capable of meeting their own energetic requirements and those of juveniles } \\
\text { in their brood because females will feed juveniles for the first } 7 \text { days after hatch (Gregg 1984, Vander } \\
\text { Haegen 1992). }\end{array}$ \\
\hline
\end{tabular}




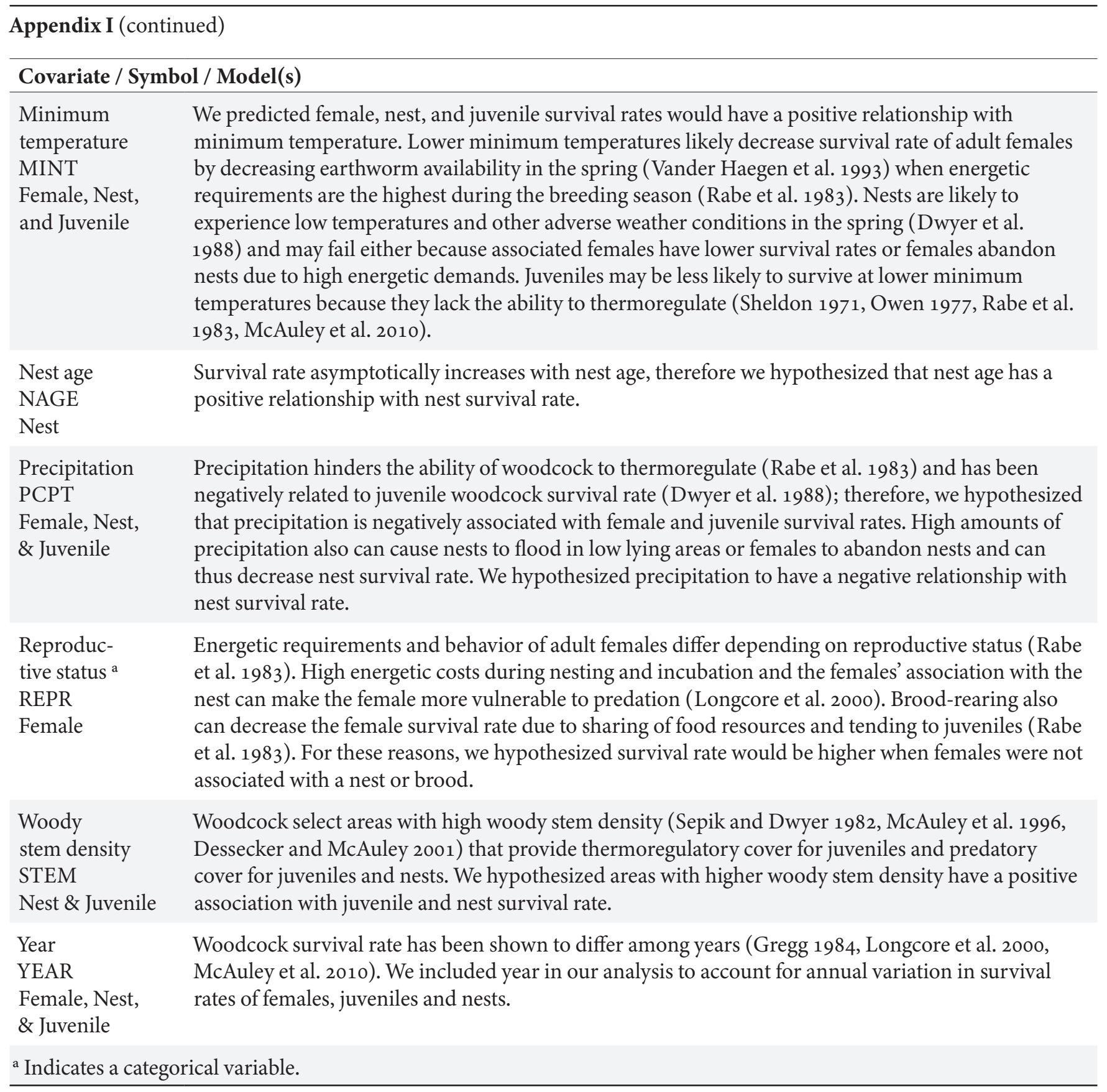


Appendix II. Assessment of independence of survival among brood mates of juvenile American woodcock monitored via radio telemetry at Tamarac National Wildlife Refuge, Minnesota, USA, during 2011 and 2012. We used survival data from broods with $>1$ juvenile at the time of capture and radio attachment $(n=38)$, and conducted 50 iterations of estimates of survival rate, randomly partitioning broods in each iteration to estimate daily survival rate using data from half the broods $(n=19)$ and using data from the remaining half of the broods $(n=19)$ to derive a chi-square statistic based on observed and expected number of juveniles alive and dead at the end of the 15-day survival period. Average P-value for these 50 iterations was 0.3239 , indicating no support for the null hypothesis of inter-dependence among survival of brood mates.

Table AII.1. Brood identification (Id), number of juveniles in a brood when first observed and on day 15, the sum of exposure days for radio-marked juveniles, the number of days a brood was monitored up to 15 days post hatch, and the number of losses during the observation period for American woodcock monitored at Tamarac National Wildlife Refuge in northwestern Minnesota, USA, during 2011 and 2012.

\begin{tabular}{|c|c|c|c|c|c|c|c|c|c|c|c|}
\hline 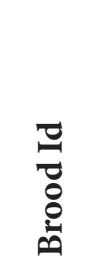 & 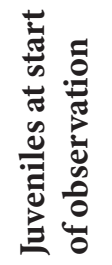 & 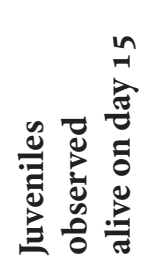 & 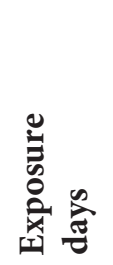 & 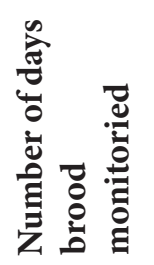 & 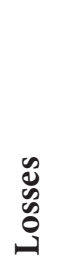 & 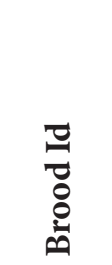 & 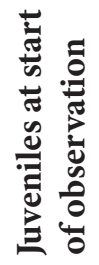 & 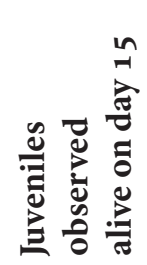 & 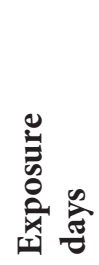 & 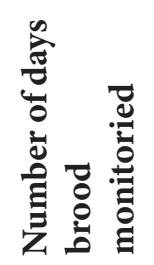 & 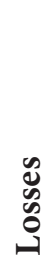 \\
\hline $11 \mathrm{AA}$ & 3 & 3 & 15 & 5 & 0 & $11 \mathrm{Y}$ & 2 & 1 & 14.5 & 10 & 1 \\
\hline $11 \mathrm{~B}$ & 4 & 4 & 32 & 8 & 0 & $12 \mathrm{~B}$ & 4 & 4 & 48 & 12 & o \\
\hline $11 \mathrm{BB}$ & 4 & 1 & 52.5 & 15 & 3 & $12 \mathrm{BB}$ & 4 & 4 & 36 & 9 & 0 \\
\hline${ }_{11 C}$ & 2 & 2 & 6 & 3 & 0 & $12 \mathrm{C}$ & 3 & 2 & 24.5 & 12 & 1 \\
\hline $11 \mathrm{E}$ & 2 & 0 & 14 & 7 & 2 & $12 \mathrm{CC}$ & 2 & 1 & 14.5 & 11 & 1 \\
\hline $11 \mathrm{~F}$ & 4 & 4 & 24 & 6 & 0 & $12 \mathrm{E}$ & 4 & 4 & 36 & 9 & o \\
\hline $11 \mathrm{G}$ & 2 & 2 & 30 & 15 & 0 & $12 \mathrm{FF}$ & 3 & 2 & 18.5 & 8 & 1 \\
\hline $11 \mathrm{I}$ & 3 & 3 & 45 & 15 & 0 & $12 \mathrm{G}$ & 4 & 3 & 23 & 7 & 1 \\
\hline $11 \mathrm{~J}$ & 3 & 2 & 10 & 4 & 1 & $12 \mathrm{H}$ & 4 & 4 & 44 & 11 & 0 \\
\hline $11 \mathrm{~K}$ & 2 & 2 & 8 & 4 & 0 & $12 \mathrm{HH}$ & 4 & 4 & 60 & 15 & 0 \\
\hline $11 \mathrm{~L}$ & 3 & 3 & 9 & 3 & 0 & $12 \mathrm{I}$ & 4 & 4 & 16 & 4 & 0 \\
\hline $11 \mathrm{M}$ & 4 & 3 & 39.5 & 11 & 1 & $12 \mathrm{LL}$ & 2 & 2 & 16 & 8 & o \\
\hline $11 \mathrm{O}$ & 4 & 2 & 42.5 & 15 & 2 & $12 \mathrm{M}$ & 3 & 3 & 42 & 14 & 0 \\
\hline $11 R$ & 2 & 1 & 15 & 14 & 1 & $12 \mathrm{O}$ & 4 & 2 & 44 & 13 & 2 \\
\hline $11 \mathrm{~S}$ & 3 & 2 & 39.5 & 15 & 1 & $12 \mathrm{Q}$ & 3 & 3 & 9 & 3 & 0 \\
\hline $11 \mathrm{~T}$ & 2 & 2 & 28 & 14 & 0 & $12 \mathrm{R}$ & 4 & 4 & 12 & 3 & 0 \\
\hline $11 \mathrm{U}$ & 2 & 2 & 12 & 6 & 0 & $12 \mathrm{~T}$ & 3 & 3 & 9 & 3 & 0 \\
\hline $11 \mathrm{~V}$ & 4 & 2 & 28 & 10 & 2 & $12 \mathrm{U}$ & 4 & 4 & 36 & 9 & o \\
\hline $11 \mathrm{X}$ & 3 & 1 & 30 & 15 & 2 & $12 \mathrm{Y}$ & 4 & 4 & 44 & 11 & 0 \\
\hline & & & & & & Total & 121 & 99 & 1027 & - & 22 \\
\hline
\end{tabular}

Mayfield Daily Survival Rate (DSR) estimate $=0.9786$

Period Survival Rate (PSR; 15 days) estimate $=0.7227$ 
Table AII.2. Mayfield survival rate estimate and Chi-square test for independence from 1 iteration used in Winterstein's third Chi-square test (Winterstein 1992) for independence within broods of juvenile American woodcock at Tamarac National Wildlife Refuge in northwestern Minnesota, USA, during 2011 and 2012 using a randomly partitioned data set ( $n=38$ broods).

\begin{tabular}{|c|c|c|c|c|c|c|c|c|c|}
\hline \multicolumn{3}{|c|}{$\begin{array}{c}\text { Mayfield estimate } \\
\text { to } 15 \text { days }\end{array}$} & \multicolumn{7}{|c|}{ Chi-square test } \\
\hline $\begin{array}{l}\text { Brood } \\
\text { ID }\end{array}$ & Losses & Exposure days & $\begin{array}{l}\text { Brood } \\
\text { ID }\end{array}$ & Obs. & Exp. & $\chi^{2}$ & Obs & Exp. & $\chi^{2}$ \\
\hline $12 \mathrm{HH}$ & 0 & 60 & $12 \mathrm{~B}$ & 4 & 3.106 & 0.257 & 0 & 0.894 & 0.894 \\
\hline $12 \mathrm{LL}$ & 0 & 16 & $12 \mathrm{Q}$ & 3 & 2.816 & 0.012 & 0 & 0.184 & 0.184 \\
\hline $11 \mathrm{R}$ & 1 & 15 & $11 \mathrm{M}$ & 3 & 3.172 & 0.009 & 1 & 0.828 & 0.036 \\
\hline $12 \mathrm{M}$ & 0 & 42 & ${ }_{11} \mathrm{C}$ & 2 & 1.877 & 0.008 & 0 & 0.123 & 0.123 \\
\hline $12 \mathrm{E}$ & 0 & 36 & $11 \mathrm{~K}$ & 2 & 1.838 & 0.014 & 0 & 0.162 & 0.162 \\
\hline $12 \mathrm{R}$ & 0 & 12 & $11 \mathrm{~T}$ & 2 & 1.489 & 0.175 & 0 & 0.511 & 0.511 \\
\hline $12 \mathrm{C}$ & 1 & 24.5 & $11 \mathrm{G}$ & 2 & 1.458 & 0.202 & 0 & 0.542 & 0.542 \\
\hline $11 \mathrm{E}$ & 2 & 14 & $11 \mathrm{Y}$ & 1 & 1.620 & 0.237 & 1 & 0.380 & 1.011 \\
\hline $11 \mathrm{~V}$ & 2 & 28 & $12 \mathrm{FF}$ & 2 & 2.535 & 0.113 & 1 & 0.465 & 0.614 \\
\hline${ }_{12} \mathrm{CC}$ & 1 & $14 \cdot 5$ & $11 \mathrm{I}$ & 3 & 2.187 & 0.302 & 0 & 0.813 & 0.813 \\
\hline $12 \mathrm{U}$ & 0 & 36 & $11 \mathrm{~F}$ & 4 & 3.525 & 0.064 & 0 & 0.475 & 0.475 \\
\hline $12 \mathrm{I}$ & 0 & 16 & $11 \mathrm{BB}$ & 1 & 2.916 & 1.259 & 3 & 1.084 & $3 \cdot 386$ \\
\hline $12 \mathrm{~T}$ & 0 & 9 & $11 \mathrm{U}$ & 2 & 1.762 & 0.032 & 0 & 0.238 & 0.238 \\
\hline $11 \mathrm{O}$ & 2 & 42.5 & $11 \mathrm{~B}$ & 4 & 3.379 & 0.114 & 0 & 0.621 & 0.621 \\
\hline $11 \mathrm{AA}$ & 0 & 15 & $11 \mathrm{X}$ & 1 & 2.187 & 0.644 & 2 & 0.813 & 1.732 \\
\hline $11 \mathrm{~J}$ & 1 & 10 & $11 S$ & 2 & 2.187 & 0.016 & 1 & 0.813 & 0.043 \\
\hline $12 \mathrm{BB}$ & 0 & 36 & $12 \mathrm{H}$ & 4 & 3.172 & 0.216 & 0 & 0.828 & 0.828 \\
\hline $12 \mathrm{Y}$ & 0 & 44 & $12 \mathrm{G}$ & 3 & 3.451 & 0.059 & 1 & 0.549 & 0.371 \\
\hline $11 \mathrm{~L}$ & 0 & 9 & $12 \mathrm{O}$ & 2 & 3.041 & 0.357 & 2 & 0.959 & 1.131 \\
\hline Total & 10 & 479.5 & Total & 47 & $47 \cdot 720$ & 4.091 & 12 & 11.280 & 13.713 \\
\hline \multicolumn{3}{|c|}{$\widehat{S}=0.9791$} & $\begin{array}{l}\text { Total } \chi^{2} \\
\text { Degree } \\
P=0.4\end{array}$ & $\begin{array}{l}.091+13 \\
\text { freedom }\end{array}$ & $\begin{array}{l}3=17.804 \\
18\end{array}$ & & & & \\
\hline
\end{tabular}

